\title{
A tela de palavras: Tradução dos poemas de Tenzing Rigdol
}

\author{
Elton Luiz, Aliandro Furlanetto
}

\begin{abstract}
Resumo: O texto a seguir tem por objetivo apresentar a tradução feita por mim de dois poemas do poeta e artista plástico tibetano Tenzing Rigdol. Primeiramente, apresento alguns pressupostos da tradução de poesia, para justificar meu processo de trabalho tradutório. Depois, apresento brevemente o poeta, e cada um de seus poemas, com comentários sobre os elementos poéticos e as principais dificuldades encontradas. Termino com um breve comentário da importância da tradução de poesia tibetana no contexto atual brasileiro.
\end{abstract}

Palavras-chave: Tenzing Rigdol; Paulo Henriques Britto; pintor e poeta Tibetano; tradução poetica

\begin{abstract}
The following text aims at presenting the translation I made of two poems by Tibetan poet and fine artist Tenzing Rigdol. First, I comment on some premises of poetry translation, to justify my translation working process. After that, I briefly introduce the poet, and each of the selected poems, with comments about the poetic elements and the obstacles I encountered while translating. I conclude with a brief testimony of the importance of translating Tibetan poetry in our current Brazilian context.
\end{abstract}

Keywords: Tenzing Rigdol; Paulo Henriques Britto; Tibetan poet and painter; poetic translation 


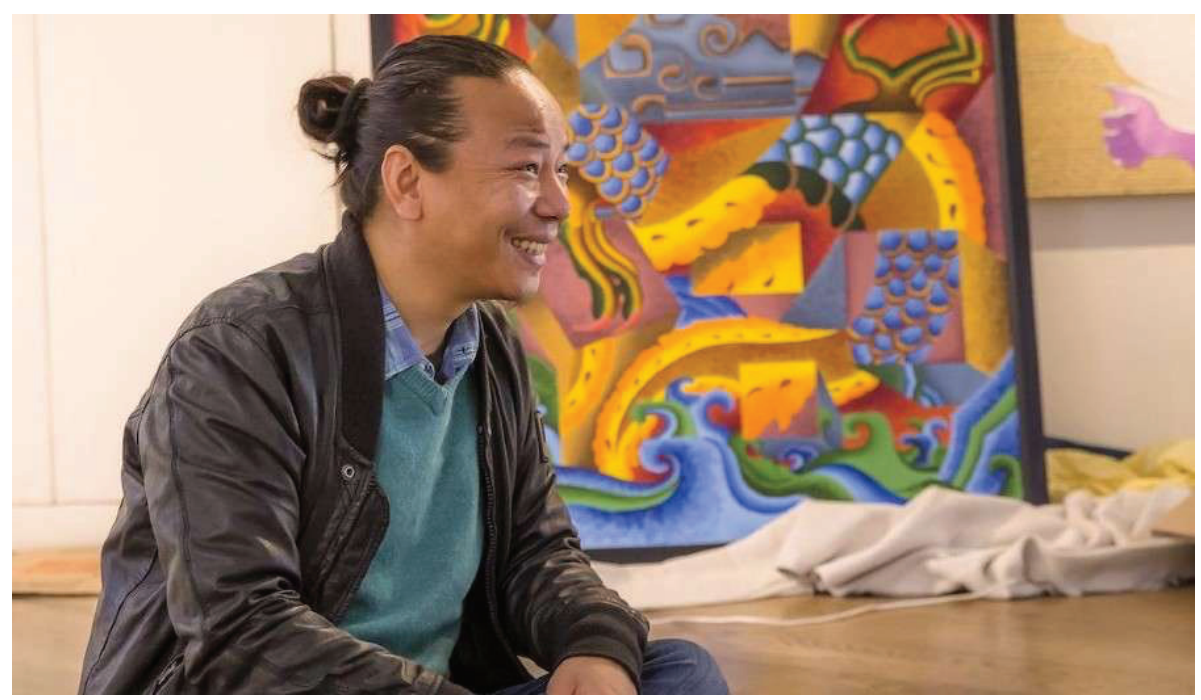

\section{Apresentação}

Meu percurso enquanto tradutor de poesia começou de forma não tradicional. Como leitor de poesia, e estudioso da obra da escritora estadunidense Marge Piercy, fui convidado por uma amiga, que havia lançado um periódico acadêmico, a Revista Almatroz, para realizar uma tradução comentada de alguns poemas da autora. O resultado foi a publicação de três poemas originais com suas traduções e alguns comentários, que podem ser vistos em Furlanetto (2013). À época, ainda não havia estudado as grandes tradições de tradução poética no Brasil e os comentários tenderam a ser mais intuitivos do que técnicos.

No entanto, a realização de tal tradução me fez entrar em um contato mais aproximado com a autora. E me fez desenvolver um plano de estudos sobre tradução, para que eu pudesse contar menos com a intuição e pudesse embasar cientificamente meu processo tradutório. Para tanto, diversas obras foram relevantes na busca por uma melhor compreensão da tradução de poesia.

Um dos primeiros trabalhos consultados foi o livro Poética da Tradução (1993) de Mário Laranjeira. Por meio dele, pude estar em contato com aspectos mais linguísticos do processo tradutório, especialmente destacando conceitos como a semiótica, a semanálise, a fidelidade e reescritura na tradução de poesia. Dele, parti para dois trabalhos mais recentes, ambos publicados em 2012. O primeiro 
foi Traduzir o poema, de Álvaro Faleiros, que inicia sua obra explicando sobre as abordagens da tradução poética no Brasil, explicitando um percurso histórico bastante informativo do campo no país. Os capítulos seguintes se organizam por elementos poéticos explicados e exemplificados, por poemas traduzidos a partir do francês, língua principal de trabalho do autor. Temos dicas sobre a tradução do espaço gráfico, metro, rima e verso livre.

Por fim, na segunda obra, A tradução literária, de Paulo Henriques Britto, o autor faz uma síntese da história dos Estudos de Tradução no Brasil, seguida por dois capítulos, um sobre a tradução de ficção (prosa) e outro pela tradução poética. Apesar de ser um livro que se orienta para uma introdução aos temas, ele foi muito relevante para pautar minha visão sobre a tradução poética. Segundo o autor,

Temos consciência de que o texto poético trabalha com a linguagem em todos os seus níveis - semânticos, sintáticos, fonéticos, rítmicos, entre outros. Idealmente, o poema deve articular todos esses níveis, ou pelo menos vários deles, no sentido de chegar a um determinado conjunto harmônico de efeitos poéticos. A tarefa do tradutor de poesia, será, pois, a de recriar, utilizando os recursos da língua-meta, os efeitos de sentido e forma do original - ou, ao menos, uma boa parte deles. (BRITTO, 2012, p. 54).

Como a obra de Britto é bastante diversificada, seus artigos acadêmicos complementam os conteúdos do seu livro. Um em especial traz uma conceituação que me interessa bastante e identifica a metodologia de trabalho que sigo. Trata-se de "Tradução e Criação", publicado em 1999. Neste artigo, Britto registra um de seus modos de trabalho na tradução poética: um movimento pendular, que se movimenta de uma autonomização do texto traduzido, com relação ao texto-fonte. Esse distanciamento se configura como uma despreocupação com o nível formal do poema original, realizando uma tradução mais literal, mais focada em aspectos do significado bruto.

O pêndulo se movimenta, e o passo seguinte é a aproximação do texto aos aspectos formais e semânticos trazidos pelo poema. Por mais que haja nesse ponto um aparente afastamento dos termos e ordem sintática, por vezes acréscimos ou exclusões, tendo em base o texto-fonte, há, na realidade, uma aproximação aos efeitos de sentido construídos pelos mecanismos poéticos.

Tendo esse percurso como pressuposto, sigo para a experiência de tradução em foco neste texto: convidado para participar do projeto de tradução de poetas tibetanos, a organizadora das traduções me enviou 4 de seus poemas. Depois de ter lido os poemas, como eu desconhecia o poeta e artista Tenzing Rigdol, 
o primeiro passo que tomei foi me informar de maneira crítica sobre o sujeito produtor de poesia. Detalhes biográficos e da poética geral de qualquer autoria podem iluminar aspectos específicos dos poemas: um exemplo bastante revelador aqui é o conhecimento de que Rigdol, além de poeta, é artista plástico. Tais combinações de diferentes linguagens tendem a se afetar mutuamente, trazendo para sua produção escrita um cuidado com a cor e com a visualidade. Por esse motivo, a próxima seção tem como objetivo uma breve apresentação do artista.

\section{O poeta}

Para nos informar a respeito do poeta tibetano, que vive nos Estados Unidos, foi muito relevante o artigo "Searching for Tibetanness: Tenzing Rigdol's Attempt to Visualize Tibetan Identity" de Eva Maria Seidel, da Universidade de Bonn, na Alemanha. O artigo se divide em diversas partes: fala do artista, de sua arte, de seu ser tibetano (Tibetanness) e sua identidade tibetana. É curioso perceber que o ser tibetano para Rigdol difere um pouco do que se estabelece nas discussões teóricas sobre o assunto (por isso a parte final do artigo de Seidel é chamada de “a definição de 'ser tibetano' de Tenzing Rigdol).

Seidel nos conta que os pais de Rigdol fugiram do Tibete durante os anos 1950 para o Nepal, onde ele nasce em 1982, em Katmandu. Viveu em Dharamsala, onde aprendeu sobre carpetaria, colagem tibetana tradicional e arte thangka (arte originária do Tibete, ligada ao budismo). Além disso, estudou pintura em areia e escultura em manteiga. Em 2002, ele foi aos Estados Unidos e começou a estudar arte ocidental, mas percebeu que queria entender mais sobre as artes tradicionais de suas origens, então voltou ao Nepal e Índia, depois retornou aos Estados Unidos para obter seu diploma em Artes Plásticas pela Universidade do Colorado.

Rigdol é pintor, escultor, realiza colagens e instalações e mora em Nova York. Ficou conhecido em 2013 por fazer o documentário Bringing Tibet Home (Trazendo o Tibete para casa) no qual ele conta suas desventuras em levar 20 toneladas de terras tibetanas para Dharamsala para realizar a instalação Our land, our people (nossa terra, nossa gente), para que as pessoas tibetanas que moravam na cidade indiana pudessem pisar na terra natal novamente, tocá-la e depois dizer como se sentiram em um microfone.

Em diversas entrevistas, Rigdol indicou o desejo de voltar ao Tibete porque ele só conhece por meio de relatos dos pais, amigos e da mídia. Um aspecto interessante indicado pela autora do artigo é que 
Rigdol tries to find the Tibetan in himself. He holds that his research is on what it means to be a Tibetan or what Tibetanness is. But as stated, his focus is also outwards, towards finding the Tibetanness in traditional Tibetan art and in his life inside and outside of the Tibetan community. He is not alone in this aim; many artists like Losang Gyatso (Virginia, USA), Gonkar Gyatso (Chengdu, PRC) and Gade (Lhasa, TAR) are depicting their own struggles with Tibetan identity, the different cultures they have lived in or their own opinions about Tibet and its changing culture. (SEIDEL, 2016, p. 375)

Dessa forma, a obra de Rigdol, em qualquer uma das suas modalidades indica esse esforço de compreensão e construção da identidade tibetana, a partir de um olhar externo, mas mediado pela sua vivência e pesquisa, e principalmente pela sua arte.

\section{Os poemas}

Em posse dessa fundamentação, e com os poemas "Untitled", "Offering”, "A poem on Tibetans' self-immolation" e "Monsoon" para traduzir, parti para a tradução inicial, na qual eu buscaria entender em linhas gerais e de forma bruta como os significados se construíram no original e eles mediariam o processo de encontro de seus equivalentes na língua portuguesa. Vou selecionar apenas dois dos poemas traduzidos para ilustrar os pontos aqui.

Vou apresentar apenas dois desses poemas e suas respectivas traduções: "Untitled" e "Monsoon". 
Untitled

Heaven soaked in honey

is far less seductive to me

than you

my beloved country.

Lonesome nights are many

time drips like viscous honey

and to orphans like us

there is no midnight story.

Tears swell my briny pillow

and my heart hangs heavy and low

for I am in darkness

and I don't see any crows.

\section{Sem título}

O céu ensopado de mel

me faz menos feliz

do que você

meu amado país.

São muitas noites sozinho

Cada hora escorrendo melada

e para órfãos como nós

não há história da madrugada.

Lágrimas salgam meu travesseiro

o peito me dói, é um estorvo

porque na escuridão

não vejo nenhum corvo.

No caso de "Untitled", que foi traduzido para "Sem título" (algo que acontece com certa frequência, quando escritores de poesia preferem não nomear poemas específicos, pelos mais diversos motivos), temos uma voz cujos sentimentos são aqueles de tristeza e nostalgia. O poema é direcionado a um interlocutor, o amado país, a quem a voz lírica se dirige. Palavras como "solitária", "órfãos", "lágrimas", "escuridão" servem para estabelecer o tom (mood) e tornam-se necessárias para reconstruir tal tom em português. Algumas imagens "histórias da meia-noite" e os "corvos" que ele não vê também servem para completar as referências trazidas pelos poemas.

Após essa primeira percepção, foi necessário analisar aspectos formais do poema original. Temos três quartetos, com três rimas cada, sempre no primeiro, segundo e quarto versos. Os terceiros versos, além de não fazerem parte do esquema de rimas, tendem a ser os menores versos da estrofe a que pertencem. Ainda que o poema em inglês não tenha uma metrificação padronizada para cada verso (eles variam entre um e três pés poéticos, medida utilizada naquela língua), existe uma certa uniformidade de metros, tendo os versos extensões parecidas, exceto nos terceiros versos de cada estrofe.

Cada uma das estrofes é formada por uma oração completa, segundo indica a pontuação, e há efeitos sonoros como a aliteração do /h/ nas primeira e terceira 
estrofes, e /d/ na estrofe final. Ademais, encontramos assonância do ditongo / ai/ na segunda estrofe.

Como podemos ver pela tradução, foi possível recuperar algumas das características semânticas e poético-formais do poema em questão. Mantive as palavras "órfãos", "lágrimas", "escuridão" e "sozinho", que servem para estabelecer o tom do poema, além da referência ao corvo e a dor (que serviu como uma condensação de dois adjetivos em inglês "heavy" e "low") no peito (que de forma metonímica substitui o coração do original).

As maiores dificuldades encontradas se localizam na estrofe final. Primeiramente, dois substantivos importantes do primeiro verso, "Tears" e "pillow" têm, respectivamente, uma e duas sílabas no inglês. No português, para construir essa imagem, levando em consideração o cenário noturno e o símbolo de tristeza, temos palavras que possuem muitas sílabas, lágrimas (poderia ser o choro, o pranto, ambos com a mesma extensão silábica) e travesseiro (almofada seria uma alternativa, a qual não diminui o número de sílabas. Coxim, por outro lado, é um vocábulo menor, porém muito inusual no português brasileiro contemporâneo). Por isso, escolhi por uma economia de palavras, ainda assim deixando o verso mais longo que seu original.

No verso seguinte, que também é composto por palavras com uma ou duas sílabas, foi necessária uma mudança mais profunda. Enquanto temos um conjunto de um anapesto (duas sílabas átonas e uma tônica), seguida de um metro mais raro, chamado antibáquio (duas sílabas tônicas, seguidas de uma átona), finalizando com um iambo (uma sílaba átona e outra tônica). Essa sucessão métrica dá ao verso uma particularidade de altos e baixos, que não conseguimos manter na tradução. Mais do que isso, para que o verso não ficasse tão longo, palavras gramaticais foram suprimidas, coração foi vertido por "peito" e criei uma cesura, uma interrupção não existente no original, como forma de condensar no verso as duas ideias presentes nos adjetivos "heavy" e "low", de forma que um substantivo "estorvo" seja rima com outro substantivo "corvo".

No que diz respeito à rima, é possível notar que ela foi recuperada de forma apenas parcial: em vez de três versos com rima, elas foram mantidas apenas no segundo e quarto versos de cada estrofe. Porque a rima se mantém padronizada, ainda que não na mesma quantidade, a decisão tradutória pareceu justificada. As tentativas para recuperar as três rimas de cada estrofe exigiam mudanças muito profundas nos signos apresentados pelo poema. O metro foi mantido, na medida do possível, com uma variação entre cinco e oito sílabas poéticas, exceto no segundo verso da terceira estrofe, que ficou o mais longo do poema. 
Finalmente, na questão da sonoridade, as aliterações e assonâncias foram recuperadas, de forma quase total. Na primeira estrofe, temos a recorrência da consoante inicial $/ \mathrm{m} /$, e na estrofe final temos apenas uma aliteração em $/ \mathrm{k} /$, que ocorre em posição intermediária no terceiro verso. No caso da segunda estrofe, a assonância está representada pela recorrência das vogais /o/ e /o/ (abertas e fechadas).

\section{Monsoon}

Poets and painters of all crippled towns came to see the art of pure monsoon song. The mighty nimbus had drawn a curtain over the sky, giving our old-aged moon time to orchestrate a cosmic dance. The wind that swept the seasons across gently whispered into the ears of gray clouds, "Silver pearls, silver pearls, grant them their share of laughter and cry." Underneath, the wanderers waited with their minds nailed to their temperaments; some with lurid colors on their brushes, and others with acute bamboo tips dipped into indigo inks. In the distance, a river carried the memoir of the melted sun and sailed along with surfing twigs and leaves. The king of the sky gathered their attention by announcing the dance with magical swords. The sky roared; the clouds unleashed their reserved pearls. The music had begun; the sharp arrowheads of raindrops drummed across river and trees. A soothing rhythm was summoned, and the joyous song filled the emptiness. The sky opened its clear eyes; stars glowed and dangled overhead. All the poets and painters of crippled towns stood drenched and drowned in the spell of such an aesthetic sight. Once again their weary minds found their long-lost child.

\section{Monção}

Poetas e pintores de todas as cidades devastadas vieram para ver a arte da pura canção da monção. A poderosa cúmulo-nimbo tinha colocado uma cortina sobre o céu, dando à nossa velha lua tempo para orquestrar uma dança cósmica. O vento que varria as estações para além gentilmente sussurrava nos ouvidos das nuvens cinzas: "Pérolas prateadas, pérolas prateadas, concedam a eles sua parcela de riso e choro." Lá embaixo, os andarilhos esperavam com suas mentes pregadas aos seus temperamentos; alguns com cores lúgubres nos pincéis, e outros com palitos afiados de bambu mergulhados em tintas anis. À distância, um rio carrega as memórias do sol derretido e flui com galhos e folhas boiando. O rei do céu chamou a atenção de todos ao anunciar a dança com espadas mágicas. O céu retumbou; as nuvens liberaram suas pérolas reservadas. A música tinha começado; as afiadas gotas como pontas de flecha tamborilavam no rio e nas árvores. Um ritmo calmante foi 
invocado, e a canção alegre preencheu o vazio. O céu abriu seus olhos límpidos; as estrelas balançavam e brilhavam no alto. Todos os poetas e pintores das cidades devastadas ficaram ensopados e afogados no feitiço de tal visão estética. Mais uma vez a mente cansada deles encontrou a criança há tempos perdida.

O poema em prosa "Monção", da mesma forma que um poema em verso livre, vai se valer de outras estratégias poéticas que não a rima, no caso dos poemas de verso livre, e do metro, no caso do poema em prosa. Porque esses elementos poéticos não se apresentam da mesma maneira que em poemas tradicionais, a percepção da pessoa que lê/ouve o poema precisa ser direcionada para quaisquer outras características que configurem padrões de repetições e sonoridades.

Gostaria de destacar dois fenômenos poéticos que permeiam o poema, e que foram vitais no seu processo de tradução: as metáforas de antropoformização e as abundantes aliterações e assonâncias.

A monção é um elemento geográfico natural típico do sul da Ásia, e como tal, serve como uma identificação simbólica de um determinado local. Vista de maneira ambivalente, ela é determinante para diversos aspectos da região. Ela transforma regiões desertas pela estação seca em zonas de verde e é central para a agricultura. Porém, se as monções trazem poucas chuvas, há problemas de seca e a agricultura não prospera. Por outro lado, se chove demais, há enchentes, e todos os males decorrentes delas. Talvez seja essa a razão que o poema indica que as nuvens trazem "riso e choro".

No poema, muitos dos sujeitos das frases são fenômenos da natureza. A poeticidade é amplificada pela antropomorfização de elementos como: as nuvens, a lua, o vento, o rio e o céu. Enquanto a natureza é atuante, na maioria dos verbos do poema, há humanos, os poetas, pintores e andarilhos que apenas observam e esperam as mais diversas ações realizadas pela natureza. Mesmo no caso daquelas ações que são consideradas [+humano] para as teorias da semântica, são aqueles personagens naturais que as realizam, criando até um tom místico no poema. $\mathrm{Na}$ tradução, busquei apresentar essa mesma surpresa, dos fenômenos naturais agirem de forma antropomórfica, estabelecendo as mesmas relações entre sujeitos e predicados que havia no original: as nuvens varriam, as nuvens sussurravam, o céu abriu os olhos, etc.

Tomando por base o texto original, no caso da sonoridade, podemos perceber que uma série de sons parecidos são utilizados em palavras próximas, até mesmo em palavras combinadas (unidas por uma conjunção "e”, por exemplo). 
Os sons podem aparecer em posição final da palavra, como no caso de "monsoon" e "song", "share of laughter". Esse tipo de ocorrência foi menos frequente. Quando pensamos em sons similares nos inícios das palavras, podemos criar uma lista mais extensa: "Poets" "painters" e "pure", na primeira sentença do poema. Mais adiante, há "swept", "seasons" e "silver". Expressões como "wanderers waited with" e "into indigo inks" parecem igualmente explorar essas questões de sonoridade. Quando fala do rio, temos dois sons em "memoir", "melted" e "sun and sailed", "surfing", "swords" e "sky". Mais adiante, temos "soothing" "summoned", "song" e "stars". Perto da finalização, temos ainda "drenched and drowned" e "long-lost".

$\mathrm{Na}$ tradução, por mais que houvesse uma tentativa de recuperar essa sonoridade inicial das palavras, além das raras rimas entre palavras próximas, parece que a quantidade de aliterações, assonâncias e ecos entre as palavras ficaram um pouco menos frequentes do que as ocorrências do original. Podemos destacar as seguintes manutenções: no caso de sons finais, "canção da monção" e "galhos e folhas". Já os sons iniciais criaram sonoridades similares nos seguintes casos: nas primeiras sentenças temos "poetas e pintores", "pura" e "poderosa". Além deles, "cúmulo-nimbo" "colocado" e "cortina". Adiante, "vento que varria", "pérolas prateadas" e "parcela". Os instrumentos "pincéis" e "palitos". Há "rio" e "ritmo" e "calmante" e "canção". Perto da conclusão, há a expressão "balançavam e brilhavam" e "ficaram" e "feitiço". Por ser um poema narrativo, que descreve uma situação da chuva começando, não quis utilizar palavras mais formais (como gris, no lugar de cinza, por exemplo), para não forçar sonoridades similares em detrimento da fluidez e das relações entre os significados do texto.

\section{Considerações finais}

A experiência de traduzir os poemas de Tenzing Rigdol foi bastante enriquecedora para mim. Foi meu primeiro contato com a poesia tibetana, enquanto leitor e tradutor. Isso exigiu uma maior pesquisa de contextualização e um cuidado maior na reconstrução das imagens e efeitos poéticos em português.

Uma consequência mais imediata deste trabalho, e uma das questões mais relevantes do campo da tradução, é estabelecer pontes entre diferentes culturas. O Brasil, tal como um ambiente, quase sempre em sua história, aberto aos mais diversos tipos de influências, precisa conhecer melhor a cultura oriental, nas suas mais múltiplas e variadas expressões. A arte, com seu potencial utópico e político, pode ser um dos caminhos para mediar nossa compreensão de uma história tão 
rica e complexa como a do Tỉbete, uma região não tão representada na mídia e mesmo nos materiais educativos brasileiros.

Seria interessante que houvesse mais iniciativas como estas, de tradução de artistas tibetanos, exposições de suas obras e intercâmbios dos mais diversos, para aproximar nossas culturas e nos tornar mais empáticos e curiosos.

\section{Referências bibliográficas}

BRITTO, Paulo Henriques. "Tradução e criação". In: Cadernos de Tradução. v. 1, n. 4, p. 239-262, 1999.

BRITTO, Paulo Henriques. A tradução literária. Rio de Janeiro: Editora José Olympio, 2012.

FALEIROS, Álvaro. Traduzir o poema. Cotia, SP: Ateliê Editorial, 2012.

FURLANETTO, Elton Luiz Aliandro. "Tradução Comentada de Marge Piercy". In:

Revista Almatroz. v. 1, n. 1, p. 2013.

LARANJEIRA, Mário. Poética da tradução: do sentido à significância. São Paulo: Edusp, 1993.

SEIDEL, Eva Maria. Searching for Tibetanness: Tenzing Rigdol's Attempt to Visualize Tibetan Identity. In: REVUE D’ETUDES TIBÉTAINES. n. 37, p. 374-390, 2016.

Elton Luiz Aliandro Furlanetto é graduado (bacharelado e licenciatura) em Letras - Inglês e Português pela Universidade de São Paulo (2005). Tem experiência na área de Letras, com ênfase em Literatura, atuando principalmente nos seguintes temas: ficção científica, literatura estadunidense, utopia e distopia, tradução literária, escrita criativa e ensino de línguas e literaturas. É mestre na área de Estudos Linguísticos e Literários em Inglês com enfoque na Ficção Científica e Utopia (2010). Doutor pela mesma área na USP (2015), estudou a utopia e a politização da arte, com bolsa sanduíche da CAPES na University of Florida. É pesquisador do GP Literatura e Utopia e do GREAT - Grupo de Estudos de Adaptação e Tradução. É professor na Universidade Federal do Mato Grosso do Sul (UFMS). 